УДК 53.098

\title{
ВЛИЯНИЕ ИМПУЛЬСНОГО МАГНИТНОГО ПОЛЯ НА ТОПОГРАФИЧЕСКИЕ ХАРАКТЕРИСТИКИ МОНОКРИСТАЛЛИЧЕСКОГО ГЕРМАНИЯ
}

\author{
() 2017 М. В. Гречкина, Е. Н. Бормонтов
} Воронежский государственный университет, Университетская пл., 1, 394018 Воронеж, Россия
e-mail: grechkina_m@mail.ru

Поступила в редакцию 09.02.2017 г.

\begin{abstract}
Аннотация. Проведен анализ изменения топологии поверхности германия после воздействия слабого импульсного магнитного поля методом сканирующей силовой микроскопии. Обнаружено долговременное немонотонное изменение шероховатости поверхности и микротвердости. Методом плазмохимического травления после воздействия магнитного поля выявлены дефектно-деформационные структуры на поверхности и в объеме кристалла. Обнаружено образование нанокластеров в приповерхностной области германия и проведена оценка их размеров.
\end{abstract}

Ключевые слова: сканирующая силовая микроскопия, слабое магнитное поле, германий, нанокластеры, плазмохимическое травление.

\section{ВВЕДЕНИЕ}

Воздействие слабых импульсных магнитных полей (ИМП) (<1 Тл) оказывает существенное воздействие на структуру и физические свойства твердых тел. Изменение структуры и структурнозависимых свойств полупроводниковых материалов имеет немонотонный и долговременный характер. Наблюдалось влияние магнитных полей на изменения параметров кристаллической решетки в приповерхностных слоях $\mathrm{Si}, \mathrm{Ge}, \mathrm{GaAs}$, InAs, InSb [1]; на механические свойства, на люминесценцию кристаллов [2, 3]; на изменение сорбционных свойств [4]; на релаксацию проводимости кремния. В работе [5] наблюдалась генерация дефектов и образование пространственно упорядоченных кислородно-вакансионных кластеров и преципитатов оксидных фаз в кристаллах кремния. Изменение структуры и свойств кристаллов приводит к модификации топологии поверхности исследуемых материалов и образованию различных поверхностных структур. Для исследования топологии поверхности и локальных электрофизических, механических свойств материалов с высоким пространственным разрешением используются методы сканирующей силовой микроскопии [6].

Целью настоящей работы является исследование методом сканирующей силовой микроскопии изменений топологии поверхности и поверхност- ных свойств монокристаллического германия после кратковременного воздействия ИМП.

\section{ОБЪЕКТЫ И МЕТОДЫ ИССЛЕДОВАНИЯ}

В данной работе в качестве объекта исследования использовались полированные пластины монокристаллического германия с кристаллографической ориентацией плоскостей (111), легированные сурьмой, с удельным сопротивлением $\rho=9$ Ом·см. Кристаллы были выращены методом Чохральского.

Образцы подвергались воздействию импульсного магнитного поля (ИМП) с индукцией $B=0.12$ Тл, длительностью импульсов $\tau=3 \cdot 10^{-5} \mathrm{c}$ и частотой следования $f=50$ Гц. Длительность обработки 30 с. Магнитное воздействие и хранение образцов осуществлялись при комнатной температуре. Контролировались изменения топологии поверхности, механические свойства, поверхностная проводимость.

Исследование топологии поверхности проводилось методом сканирующей силовой микроскопии (ССМ) в контактном режиме с использованием сканирующего зондового микроскопа (C3M) Femtoscan 001. ССМ позволяет получать изображения поверхности образцов и проводить измерения ее параметров с субнанометровым разрешением. Параметры шероховатости рассчитывались по 
данным ССМ с использованием программного обеспечения Femtoscan Online.

Микротвердость поверхности германия измерялась на микротвердомере ПМТ-3 с нагрузкой 100 г. Расчет проводился по методу Виккерса.

Плазмохимическое травление (ПХТ) поверхности образцов проводилось в плазме $\mathrm{CF}_{4}$ с содержанием $\mathrm{O}_{2}$ порядка $20 \%$, время травления варьировалось от 1 до 9 минут.

Поверхностная проводимость германия исследовалась методом отображения сопротивления растекания на C3M Solver P47 Pro. При сканировании использовались кантилеверы с проводящим покрытием CSG 01/ Pt с радиусом закругления острия зонда 30 нм.

\section{ЭКСПЕРИМЕНТАЛЬНАЯ ЧАСТЬ}

Изменение топографии исследуемой поверхности после воздействия импульсного магнитного поля контролировалось при фиксированной началь-

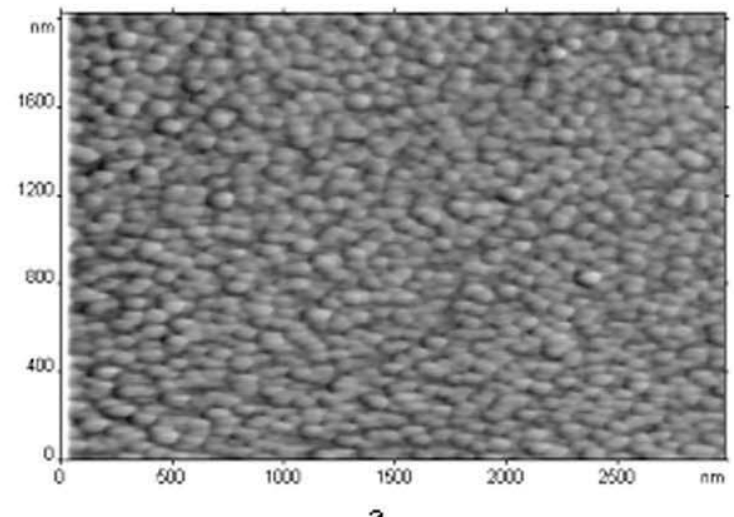

a

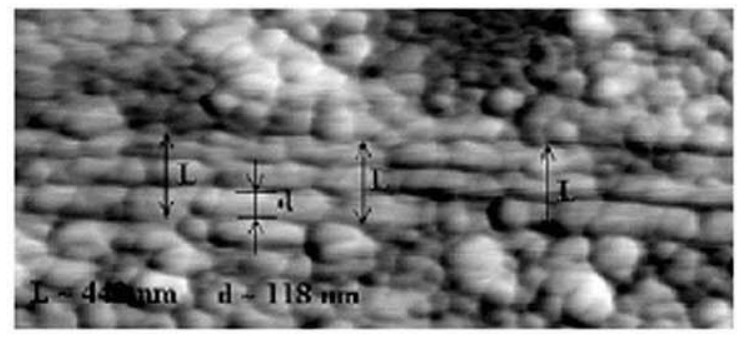

C

Рис. 1. АСМ-изображение поверхности германия через 96 часов после воздействия импульсного магнитного поля: $a$ - поверхность исходного образца, $b$ - топография поверхности после ИМП; $c$ - сечения рельефа

[Fig. 1. AFM-image of a surface of Ge through 96 hours of exposure to pulsed magnetic fields; $a$ - the surface of the original, $b$ - the surface topography after PMF; $c$ - section] ной точке сканирования и неизменном положении образца периодически в течение 360 ч каждые 24 ч. Обнаружено, что магнитная обработка приводит к динамической неустойчивости рельефа поверхности германия в течение длительного времени. Изображение исходной поверхности $\mathrm{Ge}$ показано на рис. $1 a$. Через 72 ч после воздействия ИМП отмечено образование на поверхности Ge двух типов структур: изотропных фрактальных и квазипериодических полигональных (рис. $1 b, c$ ). Размеры фрактальных структур составили 900-1250 нм, полигональных - порядка 118-150 нм. Методами сеток и Фурье-анализа оценена фрактальная размерность кратеров структур, которая составила 1.76.

Для выявления изменений рельефа по данным ССМ-микроскопии рассчитывалась шероховатость поверхности (рис. 2). Обнаружено немонотонное изменение шероховатости с течением времени с минимальными значениями через 120-144 ч после

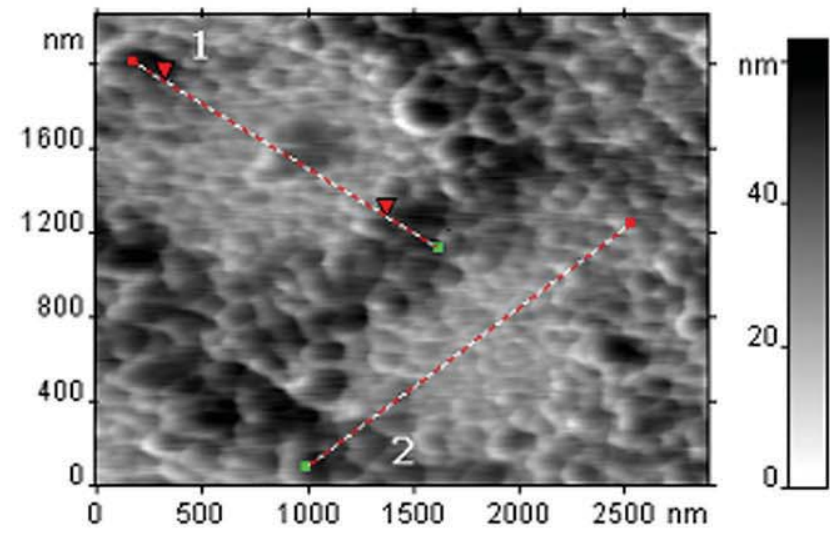

b
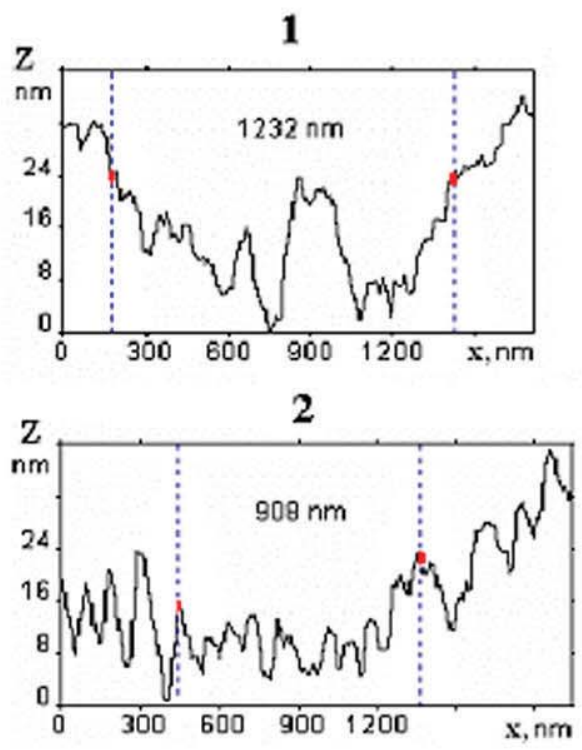

d 


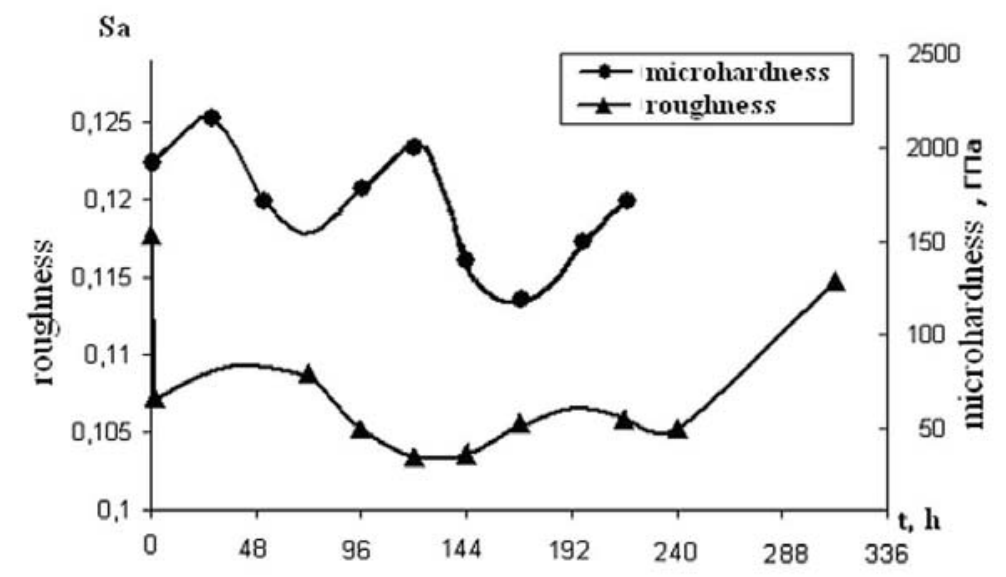

Рис. 2. Зависимость изменения микротвердости и шероховатости поверхности от времени после воздействия импульсного магнитного поля

[Fig. 2. The dependence of the microhardness and surface roughness from time after exposure to pulsed magnetic fields]

обработки и последующей релаксацией до значения, близкого к исходному, через 312 ч.

Одновременно с контролем топологии поверхности после ИМП исследовалось изменение механических свойств германия. По результатам измерений можно сделать вывод, что за период исследования значение микротвердости уменьшалось немонотонно, минимальное значение было зафиксировано через 168 ч после воздействия поля (рис. 2). Таким образом, магнитное поле приводит к изменениям структуры, термодинамических и механических свойств, что в свою очередь вызывает изменение топографических характеристик монокристалла германия.

Для изучения влияния ИМП на дефектную структуру $\mathrm{Ge}$ проводилось послойное стравливание методом плазмохимического травления $\left(\mathrm{CF}_{4}+20 \% \mathrm{O}_{2}\right)$ на контролируемую глубину 100 , 500 и 2000 нм. Динамику изменения поверхности $\mathrm{Ge}$ после воздействия ИМП и травления исследовали методом сканирующей силовой микроскопии в контактном режиме по всей поверхности образца в течение нескольких месяцев. Характерное изображение поверхности контрольного образца и образцов, протравленных на различную глубину, представлены на рис. 3 .

Поверхность контрольного образца представляла собой мелкозернистую структуру с неоднородностью рельефа не превышающей 10 нм. Обработка магнитным полем и последующее травление кристалла на глубину 100 нм привели к образованию ориентированно деформированной структуры рельефа (рис. $3 b$ ). Образованные возвышенности рельефа в виде полос имели высоту порядка 10 нм. В результате высота рельефа поверхности увеличилась до $25 \div 35$ нм. Кроме того, были обнаружены парные кластеры нанометровых размеров. Концентрация кластеров на поверхности составила $N=4.4 \cdot 10^{8} \mathrm{~cm}^{-2}$. На глубине травления 2000 нм были выявлены единичные кластеры, концентрация которых на порядок ниже и составила $N=6.0 \cdot 10^{7} \mathrm{~cm}^{-2}$.

Наиболее интересная картина наблюдалась на глубине травления 500 нм. На изображении рельефа сохранялась общая деформация кристалла (рис. $3 c$ ). На этой глубине воздействие ИМП и плазмы приводит к появлению большого числа ямок травления $\left(N=4.2 \cdot 10^{9} \mathrm{~cm}^{-2}\right)$. В большинстве своем ямки травления не имели характерной кристаллографической огранки, что может свидетельствовать о том, что они обусловлены пространственно-ограниченными дефектами, и их травление происходило быстрее, чем травление кристалла без дефектов.

Концентрация кластеров составила $N=3.4 \cdot 10^{9} \mathrm{~cm}^{-2}$. По форме наблюдаемые кластеры можно разделить на круглые и овальные (к которым также были отнесены кластеры более сложной формы, часть из которых состояли из 2-х или нескольких круглых) (рис. 4).

Расчет распределения нанокластеров по размерам при различной глубине травления представлен на рис. 5. Распределение овальных кластеров по размерам при глубине травления 100 нм имело сложную форму. Наибольшее количество овальных кластеров при глубине травления 500 нм имели размер от 75 до 135 нм, круглые кластеры от 44 до 85 нм. На глубине травления 2000 нм наблюдалась 


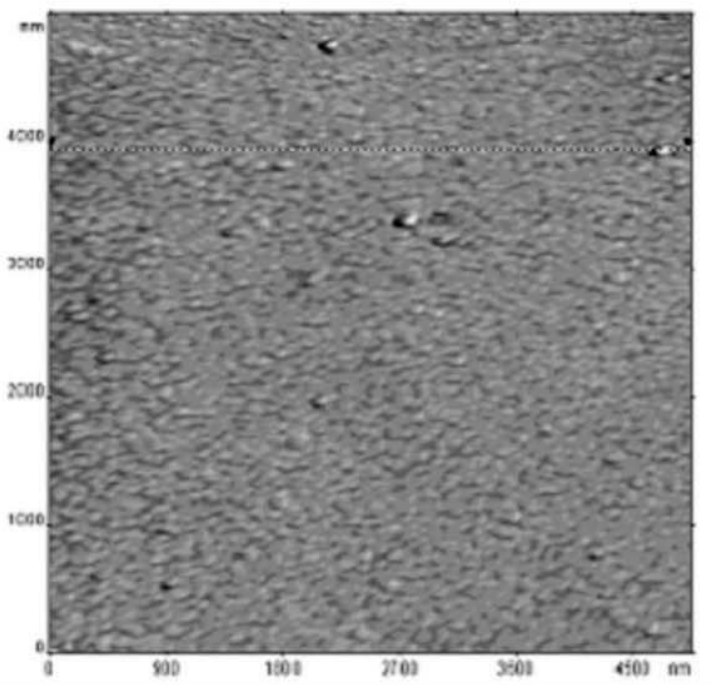

a

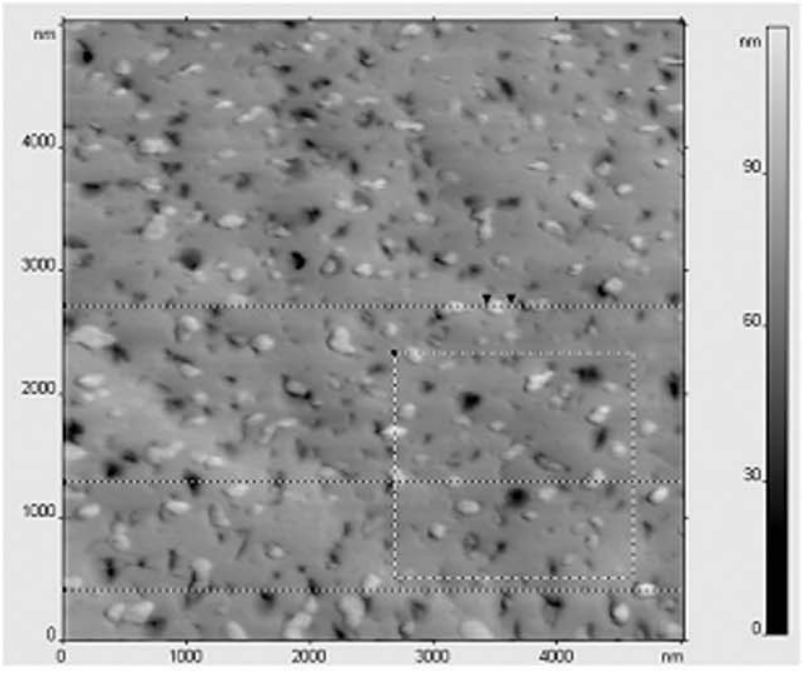

C

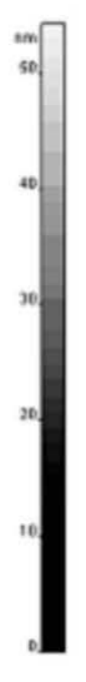

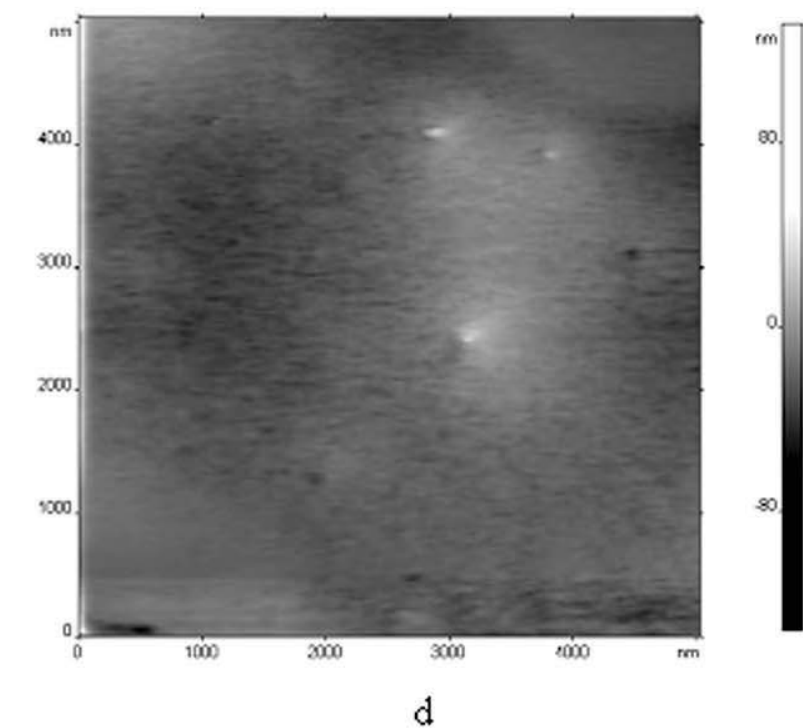

Рис. 3. Изображение поверхности германия после воздействия магнитного поля и последующего плазмохимического травления: $a$ - исходная поверхность после воздействия без травления; $b, c$ и $d$ - глубина травления 100,500 и 2000 нм соответственно

[Fig. 3. The image of a germanium surface after exposure to a magnetic field and subsequent plasma-chemical etching: $a$ - the original surface after exposure without etching; $b, c, d$ - the depth of etching 100,500 and $2000 \mathrm{~nm}$, respectively]

малая концентрация кластеров, при этом они имели сложную форму и их размеры достигали до 900 нм.

При исследовании изменений топологии поверхности после магнитного поля и травления на глубину 500 нм в течение 13 суток было обнаружено, что с течением времени происходит перестройка кластеров и соответственное сужение распределения кластеров по размерам в сторону меньших значений (рис. 6). Для круглых кластеров размер изменялся от $50 \div 105$ нм (на 7 сутки) до $45 \div 85$ нм (на 13 сутки). Перераспределение овальных кластеров было более существенным: от $77 \div 205$ нм (7 сутки) до 75 $\div 135$ нм (на 13 сутки).

Диэлектрические свойства кластеров подтверждаются исследованиями поверхности методом отображения сопротивления растекания (резистивная микроскопия) (рис. 7).

Метод отображения сопротивления растекания позволяет обнаруживать дефекты в проводящих материалах и характеризовать материалы в терминах локального сопротивления. Метод реализуется 


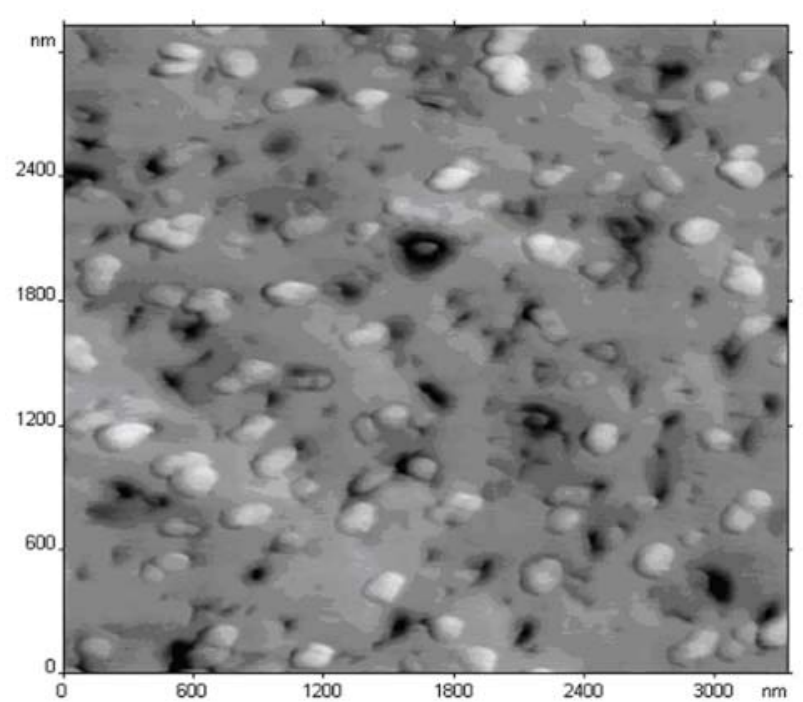

Рис. 4. Нанокластеры на поверхности германия после воздействия магнитного поля и последующего плазмохимического травления на глубину 500 нм

[Fig. 4. Nanoclusters on germanium surface after exposure to a magnetic field and subsequent plasma-chemical etching to a depth of $500 \mathrm{~nm}$ ]
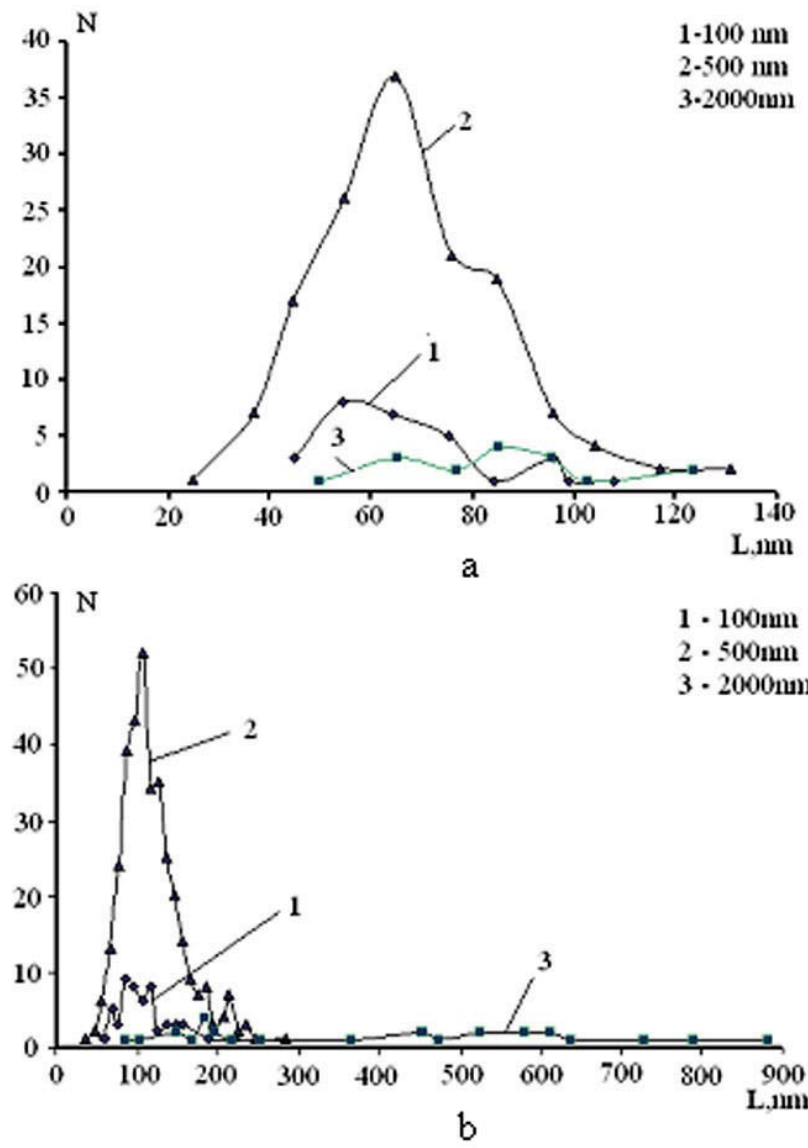

Рис. 5. Распределение нанокластеров по размерам при различной глубине травления монокристалла германия: $a$ - круглые кластеры; $b$ - овальные кластеры

[Fig. 5. The distribution of the nanoclusters in size at different depths of etching of the germanium crystal: $a$-round clusters; $b$-oval clusters]

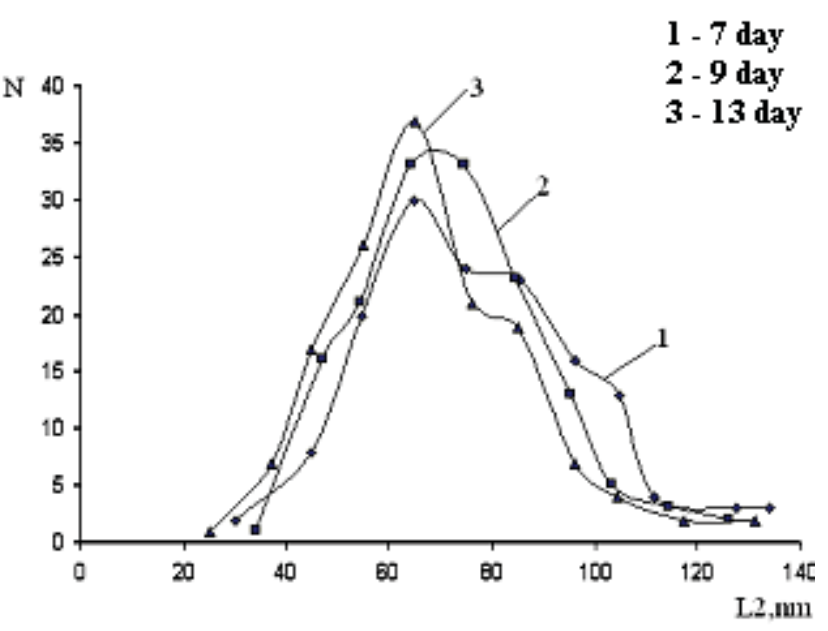

a

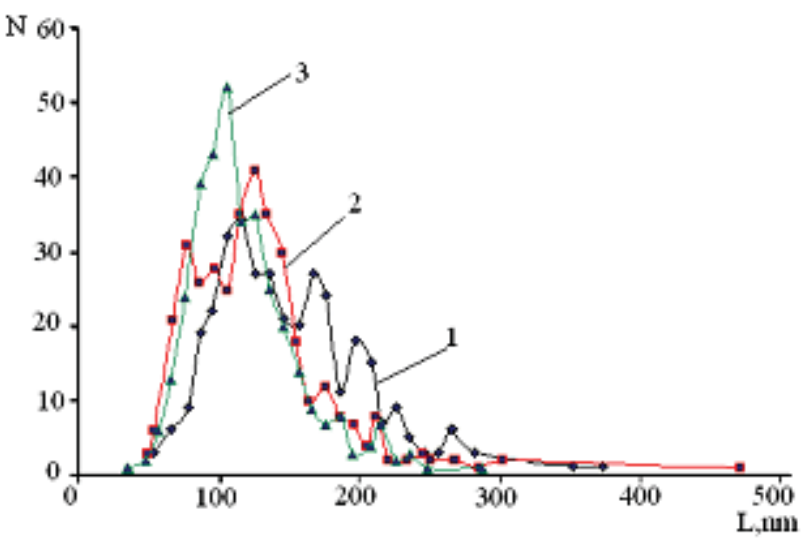

b

Рис. 6. Эволюция магнитоиндуцированных нанокластеров на поверхности Ge после ПХТ на глубину 500 нм: $a$ - круглые кластеры; $b$ - овальные кластеры

[Fig. 6. Magnetoinduction evolution of nanoclusters on the surface of Ge after plasma-chemical etching to a depth of $500 \mathrm{~nm}: a$ - round clusters; $b$ - oval clusters]

одновременно с контактным режимом постоянной силы. При сканировании зонд находится в контакте с поверхностью образца, между ними прикладывается напряжения смещения $V_{\text {Bias }}$ и измеряется результирующий ток через образец в зависимости от положения зонда одновременно с получением данных о рельефе. Предполагая, что контактное сопротивление зонд - поверхность постоянно, при заданном смещении величина измеряемого тока будет пропорциональна локальному сопротивлению исследуемого образца (поверхностной проводимости).

В работе [5] на примере кристаллов кремния показано, что воздействие импульсных магнитных полей приводит к генерации кислородсодержащих дефектов и более сложных комплексов $\mathrm{Si}_{\mathrm{x}} \mathrm{O}_{\mathrm{y}} \mathrm{V}_{\mathrm{z}}$, где $\mathrm{V}$ - вакансия. В работе [7] авторами была предло- 


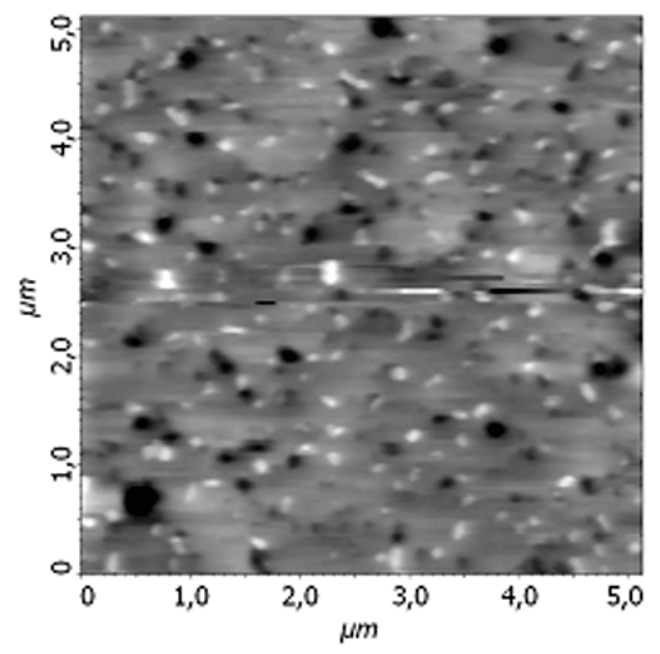

a

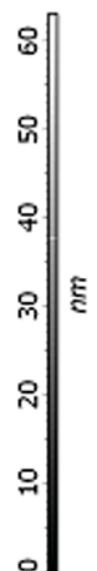

$\S$

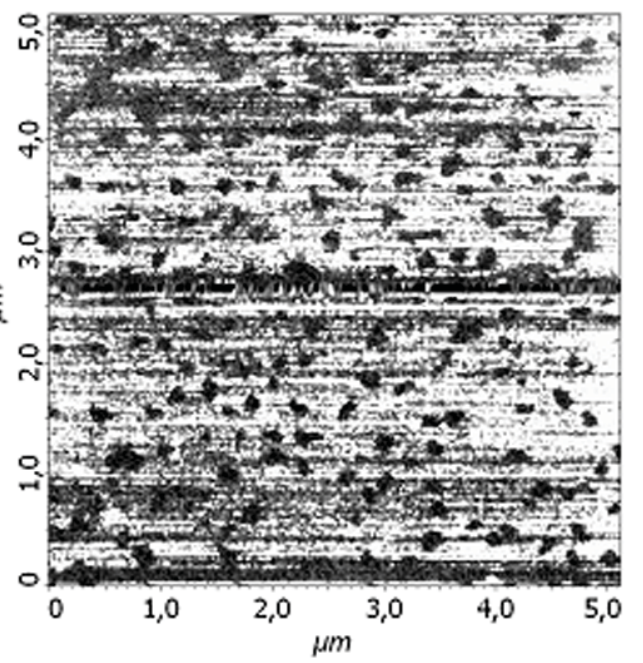

b

Рис. 7. Изображение поверхности наноструктурированного $\mathrm{Ge}$, полученное методом отображения сопротивления растекания: $a$ - топография; $b$ - поверхностная проводимость

[Fig. 7. The image of the surface of nanostructured Ge produced by the method of the spreading resistance: $a$-topography; $b$ - the surface conductivity]

жена теория, описывающая магнонный механизм реакций дефектов в твердых телах. Основываясь на этих данных и зная, что исследованные в настоящей работе кластеры не проводят ток, можно предположить, что по составу они состоят из комплексов оксида германия.

\section{ВЫВОДЫ}

В результате исследования топологии монокристаллического германия после кратковременного воздействия магнитного поля была обнаружена реструктуризация поверхности с образованием новых типов структур. Образование структур на поверхности сопровождалось немонотонным изменением шероховатости.

Изменение микротвердости германия после ИМП носило колебательный характер и приводило к уменьшению до минимального значения через 168 часов после магнитного воздействия. Эти данные коррелировали с изменениями термодинамических характеристик германия.

Методом плазмохимического травления после воздействия магнитного поля выявлены дефектнодеформационные структуры на поверхности и в объеме кристалла, обусловленные объемной генерацией дефектов. Обнаружено образование нанокластеров в приповерхностной области, максимальное количес- тво которых было выявлено при глубине травления до 500 нм. Проведена оценка размеров кластеров и обнаружена динамика уменьшения размеров до минимальных значений с течением времени.

Исследование поверхностной проводимости нанокластеров показало их диэлектрическую природу.

Результаты исследований получены на оборудовании Центра коллективного пользования научным оборудованием ВІ 'У.

\section{СПИСОК ЛИТЕРАТУРЫ}

1. Давыдов В. Н., Лоскутова Е. А., Найден Е. П. // ФTII, 1989, т. 23, вып. 9, с. 1596-1600.

2. Головин Ю. И. // ФТТ, 2004, т. 46, вып. 5, с. 769 800.

3. Головин Ю. И., Моргунов Р. Б., Баскаков А. А., Шмурак С. 3. // ФTT, 1999, т. 41. вып. 11. с. 1944-1947.

4. Левин М. Н., Татаринцев А. В., Косцова О. А., Косцов А. М. // ЖТФ, 2003, т. 73, вып. 10, с. 85-87.

5. Левин М. Н., Зон Б. А. // ЖЭТФ, 1997, т. 111, вып. 4, с. 1373-1397.

6. Миронов В. Н. Основы сканирующей зондовой микроскопии: учебное пособие для студентов стариих курсов вузов. М.: Техносфера, 2005, 143 с.

7. Белявский В. И., Иванков Ю. В., Левин М. Н. // ФTT, 2006, т. 48, вып. 7, с. 1255-1259. 


\title{
EFFECT OF PULSED MAGNETIC FIELD ON THE TOPOGRAPHIC CHARACTERISTICS OF SINGLE-CRYSTAL GERMANIUM
}

\author{
(C) 2017 M. V. Grechkina, E. N. Bormontov \\ Voronezh State University, University sq., 1, 394018 Voronezh, Russia \\ e-mail: grechkina_m@mail.ru \\ Received 09.02.2017
}

\begin{abstract}
By the method of scanning force microscopy in contact mode has been studied the change of surface topology and surface properties of single-crystal germanium (111), doped with antimony. The samples were exposed to weak pulsed magnetic fields. 72 hours after brief exposure to a pulsed magnetic field was discovered by restructuring the surface with the formation of new types of structures. The formation of structures on the surface was accompanied by a change of roughness. Minimum roughness value was observed after 144 hours after treatment. Through hours 312 the value of the roughness increased to a value close to the original.

The change of microhardness Ge after exposure to pulsed magnetic fields were carried oscillatory character and was reduced to the minimum value through 168 hours after the start of the experiment. By plasma etching after exposure to the magnetic field of the identified defective-deformation structure on the surface and in the bulk of the crystal. Revealed the formation of nanoclusters in the near surface region, the maximum number of which have been revealed by deep etching to $500 \mathrm{~nm}$. The analysis of the size of discovered clusters and the dynamics of reducing the size to a minimum over time. The method of the spreading resistance was investigated by surface conductivity of nanostructured Ge. It is shown that the nanoclusters formed have a dielectric nature.

The influence of weak magnetic field on structure of semiconductors with subsequent plasmachemical etching can be used to create a dielectric clusters in a semiconducting in the matrix.
\end{abstract}

Keywords: scanning force microscopy, weak magnetic field, germanium, nanoclusters, plasma etching.

\section{ACKNOWLEDGEMENTS}

The research results were obtained with equipment of Voronezh State University Center for Collective Usage of Scientific Equipment.

\section{REFERENCES}

1. Davydov V. N., Loskutova E. A., Naiden E. P Semiconductors, 1989, vol. 23, iss. 9, pp. 1596-1600. Available at: http://journals.ioffe.ru/articles/viewPDF/29916

2. Golovin Y. I. Physics of the Solid State, 2004, vol. 46, iss. 5, pp. 769-800. Available at: http://journals.ioffe.ru/articles/viewPDF/4223

3. Golovin Y. I., Morgunov R. B., Baskakov A. A., Shmurak S. Z. Physics of the Solid State, 1999, vol. 41, iss. 11. pp. 1944-1947. Available at: http://journals.ioffe. ru/articles/viewPDF/35596

4. Levin M. N., Tatarintzev A. V., Kostsova O. A., Kostsov A. M. Technical Physics, 2003, vol. 73, iss. 10, pp. 85-87. Available at: http://journals.ioffe.ru/articles/viewPDF/8096

5. Levin M. N., Zon B. A. Journal of Experimental and Theoretical Physics, 1997, vol. 111, iss. 4, pp. 1373-1397. Available at: http://www.jetp.ac.ru/cgi-bin/dn/r_111_1373. pdf

6. Mironov V. N. Fundamentals of Scanning Probe Microscopy, Moscow, Technosphere Publ., 2005, 143 p. (in Russian)

7. Belyavsky V. I., Ivankov Y. V., Levin M. N. Physics of the Solid State, 2006, vol. 48, iss. 7, pp. 1255-1259. Available at: http://journals.ioffe.ru/articles/viewPDF/3502
Гречкина Маргарита Владимировна - инженер кафедры физики полупроводников и микроэлектроники, Воронежский государственный университет; e-mail: grechkina_m@mail.ru

Бормонтов Евгений Николаевич - д. ф.-м. н., профессор, заведующий кафедрой физики полупроводников и микроэлектроники, Воронежский государственный университет; тел.: +7 (473) 2208481, e-mail: me144@ phys.vsu.ru
Grechkina Margarita V. - Engineer of Department of Physics of Semiconductors and Microelectronics, Voronezh State University; e-mail: grechkina_m@mail.ru

Bormontov Eugene N. - Dr. Sci. (Phys.-Math.), Full Professor, Head of Department of Physics of Semiconductors and Microelectronics, Voronezh State University; ph.: +7 (473) 2208481, e-mail: me144@phys.vsu.ru 